\title{
Tackling health inequalities and promoting prevention: If not now, then when?
}

\section{DOI: $10.7861 /$ fhj.ed.8.1.2}

When I took on the challenge of guest editing this special themed edition on inequality and prevention the COVID-19 pandemic was unravelling in Wuhan, China. That it would come to the UK in matter of weeks seemed a remote possibility; that it would exacerbate the already deepening inequalities in our society was a shock even to most seasoned of observers. 'The chilling words used by Boris Johnson in early March 2020, 'many will lose their loved ones before their time', have sadly become a grim reality for so many. The healthcare profession must now help shape the narrative that will help the nation learn, heal and move on from this dark chapter.

This past year has borne witness to a great amount of societal change. We saw the Black Lives Matter movement gain traction and worldwide climate emergency strikes - issues that affect us all. In this edition, Danso and Danso ${ }^{2}$ and Sotubo ${ }^{3}$ touch upon the structural racism encountered by Black, Asian and minority ethnic (BAME) patients and staff in the NHS and call for a strategy to tackle the inequalities that blight the healthcare experience of many. I myself am the child of immigrants, and my parents consider themselves fortunate that this land has provided them with ample opportunity; however, for some the reality of seeking a better life in UK couldn't be more different, and Worthing and colleagues examine the policies that have led to a 'hostile environment' for some NHS users. ${ }^{4}$ Meanwhile, Gopal et al's review on implicit bias offers insights on how we can best limit the damage of this human frailty in clinical practice and the wider healthcare setting. ${ }^{5}$

We require our current political leaders to wake up to the reality laid bare before us, not only in this past year, but in the austeritydominated preceding decade. How can we have an almost 10-year difference between life expectancy for men in the most deprived parts of the UK compared with the least deprived? ${ }^{6}$ It is encouraging that the RCP is at the forefront of striving for change, with the convening of over 140 organisations as the Inequalities in Health Alliance. That such a diverse range of organisations are uniting to fight this issue sends a powerful message to our political elite and I would urge all healthcare organisations to heed the RCP president's call to action. ${ }^{7}$

Looking to the future, it is exciting to see the grassroots medical student organisation Nutritank campaigning for positive change in the undergraduate medical curricula. Nutritank highlight the current lack of training in the very thing that makes us healthy nutrition - and propose their 'vision' for the doctor of the future. ${ }^{8}$ I believe that nutrition-based interventions must be integrated within our healthcare system at every level as a fundamental part of chronic disease management. ${ }^{9}$ This is further highlighted by Dixon and Ornish, who stress the need for greater social prescribing and encourage clinicians to be bold in the way they approach their communities - 'out of the consulting room and on to the streets'. 10

We know that the early years of life are extremely important; this is determined by many factors, not least parental health, and it is important that we consider the arguments for more robust postpartum care as proposed by Womersley and colleagues to help reduce the health burden in new mothers. ${ }^{11}$

Like many, this past year has given me extra cause for reflection, and it strikes me that there are more people who need help now than when I started medical school in 2006. Fitzpatrick and colleagues discuss the arguments for reform in medical education in order to equip the profession to deliver meaningful improvements in health inequalities. $^{12}$
Post-pandemic, politicians and healthcare professionals must work actively together towards a more equitable and just society where we invest in and empower the marginalised to lead better healthier lives. Just like the prime minister has announced a roadmap out of the current pandemic situation, we must all call on him for a roadmap out of the equally devastating health inequalities plaguing our society. To this end I invite you to consider the arguments by Coggon and Adams, who examine the current strategy on obesity and conclude that we need a more equitable and effective approach to achieving better public health. ${ }^{13}$

I hope you enjoy this edition. I wanted to bring together a diverse range of authors from different personal and professional backgrounds to add their perspective on how we can tackle inequality and contribute to the prevention of ill health; I am especially honoured that HRH The Prince of Wales has contributed to this edition and hope that you all wholeheartedly embrace his call for a more systemic and community-based approach to tackling ill health and inequality. ${ }^{14}$ Finally, I would like to reiterate my thanks to Dr Michael Dixon of the College of Medicine and Dr Farhang Tahzib and Prof Carol Brayne from the Faculty of Public Health among many others.

Dr Mohsin Choudry

GP registrar, Ealing General Practice Vocational Training Scheme (North West London), and national medical director's clinical fellow

\section{References}

1 Whitehead M, Taylor-Robinson D, Barr B. Poverty, health, and covid-1. BMJ 2021;372:n376.

2 Danso A, Danso Y. The complexities of race and health. FHJ 2021:8:22-7.

3 Ajayi (Sotubo). A perspective on health inequalities in BAME communities and how to improve access to primary care. FHJ 2021;8:36-9.

4 Worthing K, Mojarrieta Galaso M, Kellett Wright J, Potter JD. Patients or passports? The 'hostile environment' in the NHS. FHJ 2021;8:28-30.

5 Gopal DP, Chetty U, O’Donnell P, Gajria C, Blackadder-Weinstein J. Implicit bias in healthcare: clinical practice, research and decision making. FHJ 2021:8:40-8.

6 Williams E, Buck D, Babalola G. What are health inequalities? The King's Fund, 2020. www.kingsfund.org.uk/publications/what-are-healthinequalities.

7 Goddard A. The road to the Inequalities in Health Alliance. FH] 2021:8:9-11.

8 Xie JY-Y, Abramovich N, Burridge B et al. Nutrition education in core medical curricula: a call to action from tomorrow's doctors. FHJ 2021:8:19-21.

9 Downer S, Berkowitz S, Harlan TS et al. Food is medicine: actions to integrate food and nutrition into healthcare. BMJ 2020;369:m2482.

10 Dixon M, Ornish D. Love in the time of COVID-19: Social prescribing and the paradox of isolation. FHJ 2021;8:53-6.

11 Womersley K, Ripullone K, Hirst JE. Tackling inequality in maternal health: Beyond the postpartum. FHJ 2021:8:31-5.

12 FitzPatrick MEB, Badu-Boateng C, Huntley C, Morgan C. 'Attorneys of the poor': Training physicians to tackle health inequalities. $\mathrm{FHJ}$ 2021:8:12-18.

13 Coggon J, Adams J. 'Let them choose not to eat cake...': Public health ethics, effectiveness, and equity in government obesity strategy. FHJ 2021;8:49-52.

14 HRH The Prince of Wales. A message from HRH The Prince of Wales, honorary fellow of the Royal College of Physicians. FHJ 2021;8:5-7. 